\section{What British psychiatrists read}

\section{Questionnaire survey of journal usage among clinicians}

TERESA JONES, STEPHEN HANNEY, MARTIN BUXTON and TOM BURNS
The mission of many biomedical research funding bodies is to improve health (Wellcome Trust \& NHS Executive, 2001; Medical Research Council, 2002) but to achieve this the relevant research needs to be disseminated effectively to clinicians. Publication of research articles in peerreviewed journals plays an important part in this dissemination (Schein et al, 2000), although concerns have been raised about the effectiveness of passive dissemination in encouraging the uptake of research (Coomarasamy et al, 2001). There are few incentives for researchers to engage in research utilisation activities and the status of papers aimed at practitioners is uncertain (Tomlinson, 2000). Nevertheless, there are attempts to broaden the scope of health research assessment (Buxton \& Hanney, 1996) and to identify the journals that are important to practitioners (Lewison et al, 2001). With the current emphasis on evidence-based practice, it is critical to understand what research reaches clinicians. We undertook to obtain the views of psychiatrists on the journals that they read with regard to their clinical work and to compare these with established measures of esteem used for journals.

\section{METHOD}

Definitions for the following categories were used for psychiatrists.

(a) Child: psychiatrists specialising in the treatment of children and adolescents.

(b) Adult: general psychiatrists and those specialising in the treatment of adults of working age.

(c) Old age: psychiatrists specialising in the treatment of elderly patients.

(d) Academic: psychiatrists with any part of their contract for dedicated academic sessions (excluding routine continuing professional development). (e) Non-academic: psychiatrists without any part of their contract for dedicated academic sessions (excluding routine continuing professional development).

\section{National Health Service (NHS) Research Outputs Database}

The Research Outputs Database was constructed by The Wellcome Trust (Dawson et al, 1998) and then maintained by the Centre for Information Behaviour and the Evaluation of Research, City University. It covers the full range of research publications, including basic and clinical sciences, in the peer-reviewed journals contained in the Science Citation Index and Social Science Citation Index databases. The Research Outputs Database contains bibliographic information from biomedical papers with a UK address, including details of funding acknowledgements. The NHS Research Outputs Database, a subset of the Research Outputs Database, has been constructed and contains details of papers from England that involve some element of NHS financial support (Wellcome Trust \& NHS Executive, 2001).

The NHS papers have been identified using a filter for England that identifies them via one or more of the following: characteristics of the name of the author's institution, for example 'hospital'; the institution's postcode; or the funding acknowledgements on the paper.

\section{Journal impact factors}

Journal impact factors were obtained from the 2001 edition of the on-line Journal Citation Reports from the Institute for Scientific Information. The journal impact factor is 'a measure of the frequency with which the "average article" in a journal has been cited in a particular year or period. The annual JCR impact of a journal ... is calculated by dividing the number of current year citations to the source items published in that journal during the previous two years' (Garfield, 1994). A ranking order of journals within the 'psychiatry' category based on journal impact factors was also taken from the 2001 Journal Citation Reports for each of the citation indices (i.e. the Science Citation Index and the Social Science Citation Index). 


\section{Questionnaire survey}

\section{Psychiatrists' names and addresses}

A sample of 1200 registered Members and Fellows of the Royal College of Psychiatrists was provided by the College. The Royal College of Psychiatrists does not allow access to its membership lists but agreed to supply address labels for one-off use to distribute the questionnaires. The NHS consultant psychiatrists were selected randomly via the Statistical Package for the Social Sciences statistical software (SPSS version 10.1) from within three patient-age groups (child, adult and old age).

Psychiatrists providing services for these three patient-age groups were present in the College's membership list in the approximate proportions 1:3:1, but equal numbers from each group were included in the sample. This was to ensure sufficient numbers in each group to allow detailed analysis.

Selected UK psychiatrists were asked, by questionnaire survey, which journals they read or consulted on a regular basis with regard to their clinical practice. To ensure anonymity no record of the participants was kept.

\section{Questionnaire structure}

A list of journals containing psychiatric research was extracted from the NHS Research Outputs Database using a mental health filter previously developed for the Research Outputs Database (Wellcome Trust \& NHS Executive, 2001). The journals were ordered according to the number of papers on psychiatric research they published. To limit the list used in the study, the top 32 journals, accounting for $60 \%$ of UK psychiatry papers in the period 1990-1999, were presented in alphabetical order on the questionnaire. The questionnaire recipients were asked to tick up to ten journals that they read or consulted on a regular basis with regard to their clinical work and to rank the top three of these. In doing this they were invited to add journals missing from the list that they considered important for mental health clinical practice. They were then asked to provide brief details of the type of NHS contract they held, the number of academic and clinical sessions they worked, which patient age-group they worked with and which disorders they covered. The questionnaire is appended as a data supplement to the on-line version of this paper and is available from the authors on request.

\section{Questionnaire analysis}

The data from the returned questionnaires were entered into a database. There were difficulties in identifying all the journals added to the questionnaires by the respondents, particularly because of the similarity of some journal names; therefore, a member of the Health Economics Research Group at Brunel University (Avril Cook, see Acknowledgements) independently checked these and the journal names were verified using Ulrich's International Periodicals Directory (Bowker, 2003) or the internet.

The psychiatrists' responses were collated and tabulated according to their type of practice, and the relationships between their rankings, journal readership and impact factors were examined.

\section{RESULTS}

\section{Survey findings}

A total of 560 questionnaires $(47 \%)$ were completed and returned. The return rates for psychiatrists treating each of the three groups were: child, $49 \%$; adult, $38 \%$; old age, $52 \%$. Those psychiatrists with some academic commitment formed $26 \%$ of respondents.

A substantial number of recipients added more journals to the questionnaire, bringing the total number of journals from the original 32 up to 156 . Those journals that were not listed on the original questionnaire but appear in the summary tables have been marked with an asterisk. The 560 respondents ticked or added journal names on 3215 occasions. Out of these, $13(0.4 \%)$ related to 10 unverified journal names that nevertheless were included within the database.

The difference in the median number of journals read by psychiatrists with academic commitments (ten journals or more) and those without (three journals) was statistically significant (Kruskal-Wallis; $\chi_{1}^{2}=7.823$, $P=0.005)$. The percentage of 'non-academic' psychiatrists reading three journals or fewer was higher across all three age groupings but especially so in the adult group where the figure was $40 \%$. Overall, approximately twice as many academics compared with non-academics read at least ten journals.
Tables 1 and 2 detail the specific journals that psychiatrists read and have ranked first, second or third with regard to their clinical work. A striking consistency was found at the top of each table, both across all age groups and between academic and non-academic psychiatrists. The two most prominent journals across the board were the British Journal of Psychiatry followed by the $B M J$.

Table 1 shows that for adult psychiatrists these two journals dominated their reading habits. Both were cited by over $90 \%$ of the sample whereas the third most commonly cited journal (the American Journal of Psychiatry) was read by only $50 \%$. Although both the British Journal of Psychiatry and the BMJ were still cited by about $90 \%$ of the child and old age psychiatrists, specialised journals became more prominent.

The importance of these specialised journals for child and old age psychiatrists was even more clearly reflected in their ranking of the journals (Table 2). Within each category there were only a small number of journals (between four and seven) ranked in the top three in importance for their clinical practice by more than $10 \%$ of psychiatrists (i.e. only a few are widely viewed as important; see Table 2).

\section{Relationship of readership to the NHS Research Outputs Database and journal impact factors}

Table 3 contains the same 31 journals as those that appear in Table 1: those journals read by $10 \%$ or more of psychiatrists in any category (by patient age or academic commitments). The numbers of psychiatry papers in the journals between 1990 and 1999 were identified through the NHS Research Outputs Database. The British Journal of Psychiatry is clearly the journal with the largest number of papers in the psychiatry section of the NHS Research Outputs Database and also is ranked as the most important to clinical practice overall. The pattern needs to be interpreted with caution because only a relatively small proportion of $B M J$ papers are related to psychiatry and the Archives of General Psychiatry publishes comparatively few papers per year.

The data on journal impact factors are presented in a number of ways in Table 3, including (in the final column) their position in the Institute for Scientific Information ranking of psychiatry 
Table I Percentage of psychiatrists reading selected journals with regard to their clinical work (all journals read by at least $10 \%$ of psychiatrists in one or more category)

\begin{tabular}{|c|c|c|c|c|c|c|c|c|c|c|c|c|}
\hline \multirow[t]{3}{*}{ Journal } & \multicolumn{12}{|c|}{ Patient age-group to whom psychiatric services are provided } \\
\hline & \multicolumn{3}{|c|}{ All groups } & \multicolumn{3}{|c|}{ Child } & \multicolumn{3}{|c|}{ Adult } & \multicolumn{3}{|c|}{ Old age } \\
\hline & \pm & + & - & \pm & + & - & \pm & + & - & \pm & + & - \\
\hline British Journal of Psychiatry & 97 & 97 & 97 & 97 & 97 & 97 & 99 & 100 & 98 & 95 & 93 & 96 \\
\hline BMJ & 89 & 90 & 89 & 85 & 90 & 84 & 91 & 88 & 92 & 93 & 91 & 93 \\
\hline American Journal of Psychiatry & 38 & 48 & 34 & 25 & 32 & 22 & 50 & 73 & 41 & 39 & 44 & 38 \\
\hline Journal of Child Psychology and Psychiatry and Allied Disciplines & 35 & 41 & 32 & 96 & 100 & 94 & 3 & 5 & 3 & 0 & 0 & I \\
\hline International Journal of Geriatric Psychiatry & 30 & 27 & 31 & 0 & 0 & 0 & 3 & 2 & 3 & 80 & 93 & 76 \\
\hline Psychological Medicine & 29 & $4 I$ & 25 & 21 & 36 & 15 & 36 & 46 & 31 & 32 & 44 & 28 \\
\hline Lancet & 22 & 30 & 19 & 10 & 15 & 7 & 22 & 41 & 15 & 34 & 42 & 31 \\
\hline Age and Ageing & 16 & 14 & 18 & 0 & 0 & 0 & 2 & 0 & 3 & 43 & 47 & 43 \\
\hline Acta Psychiatrica Scandinavica & 15 & 20 & 13 & 5 & 10 & 4 & 20 & 34 & 15 & 18 & 19 & 18 \\
\hline *Journal of the American Academy of Child and Adolescent Psychiatry & 14 & 15 & 14 & 39 & 37 & 40 & I & 0 & I & 0 & 0 & 0 \\
\hline Journal of Neurology, Neurosurgery and Psychiatry & 13 & 19 & II & 3 & 7 & I & II & 22 & 7 & 24 & 33 & 22 \\
\hline Hospital Medicine (previously British Journal of Hospital Medicine) & 12 & II & 12 & 8 & 10 & 7 & 9 & 10 & 9 & 14 & 14 & 14 \\
\hline *Advances in Psychiatric Treatment & II & 6 & 13 & 14 & 8 & 16 & 13 & 2 & 17 & 7 & 5 & 8 \\
\hline *Clinical Child Psychology and Psychiatry & 9 & 10 & 8 & 24 & 24 & 24 & I & 0 & I & 0 & 0 & I \\
\hline Journal of the Royal Society of Medicine & 9 & 12 & 7 & 8 & 10 & 7 & 10 & 17 & 7 & 8 & 12 & 8 \\
\hline Biological Psychiatry & 8 & 14 & 6 & 5 & 12 & 5 & 9 & 22 & 5 & 8 & 9 & 8 \\
\hline Schizophrenia Research & 7 & 12 & 5 & 3 & 5 & 1 & 16 & 32 & 10 & 3 & 2 & 3 \\
\hline *Archives of General Psychiatry & 6 & 15 & 3 & 3 & 7 & 1 & 14 & 41 & 4 & 3 & 0 & 4 \\
\hline Journal of Affective Disorders & 6 & 12 & 3 & I & 3 & 0 & II & 32 & 3 & 6 & 9 & 6 \\
\hline Journal of Psychopharmacology & 6 & 10 & 5 & 3 & 5 & 2 & 9 & 20 & 6 & 6 & 7 & 6 \\
\hline International Journal of Eating Disorders & 5 & 5 & 4 & II & 14 & 9 & 5 & 0 & 6 & 0 & 0 & 0 \\
\hline *Journal of Family Therapy & 5 & 7 & 4 & 13 & 15 & 12 & 0 & 0 & 0 & 0 & 2 & 0 \\
\hline *Psychiatric Bulletin & 5 & 7 & 4 & 3 & 0 & 4 & 9 & 10 & 8 & 4 & 14 & 2 \\
\hline Psychopharmacology & 5 & 6 & 4 & 2 & 2 & 1 & 5 & 10 & 3 & 7 & 7 & 7 \\
\hline International Clinical Psychopharmacology & 4 & 5 & 4 & I & 0 & 1 & 6 & 15 & 3 & 5 & 2 & 6 \\
\hline *Child Abuse and Neglect & 3 & 4 & 2 & 7 & 10 & 5 & 0 & 0 & 0 & 0 & 0 & 0 \\
\hline *Journal of Adolescence & 3 & 3 & 3 & 9 & 7 & 10 & 0 & 0 & 0 & 0 & 0 & 0 \\
\hline Social Psychiatry and Psychiatric Epidemiology & 3 & 4 & 2 & 0 & 0 & 0 & 7 & 12 & 4 & 2 & 2 & 1 \\
\hline *International Psychogeriatrics & 2 & 4 & 1 & 0 & 0 & 0 & 0 & 0 & 0 & 5 & 14 & 3 \\
\hline *Ageing and Mental Health & I & 4 & 0 & 0 & 0 & 0 & 0 & 0 & 0 & 3 & 14 & 1 \\
\hline *Journal of the American Geriatrics Society & I & 3 & 0 & 0 & 0 & 0 & 0 & 0 & 0 & 3 & 12 & I \\
\hline
\end{tabular}

,\pm With and without academic commitments; + , with academic commitments; - , without academic commitments; ${ }^{*}$, journal not listed on the original questionnaire.

journals, which does not include general medical journals such as the $B M J$ or the Lancet.

\section{DISCUSSION}

The response rate of $47 \%$ to a nonclinical questionnaire survey with no reminder is somewhat better than Schein et al's (2000) response of $42 \%$ to a similar survey of American surgeons. Although this level of response indicates an interest among psychiatrists in the issue of the assessment of journals, it is possible that the non-respondents might have very different views from those discussed here.

\section{Few key journals}

For respondents, it appears that a small number of journals are very important for the dissemination of information with a bearing on clinical practice. Furthermore, the numbers of psychiatrists who read three journals or fewer are most marked in the adult group, which is approximately three times as large as the other two categories in the membership of the Royal College of Psychiatrists.
Adjustment for this factor would give overall figures for psychiatrists reading three journals or fewer of $27 \%$, with $11 \%$ for academics and $34 \%$ for nonacademics. If a small number of journals are of greatest importance to clinicians, then research findings published in these journals have greater potential to result in benefit to patients.

The journals that were found to be the most important to clinical psychiatrists the British Journal of Psychiatry and the $B M J$ - are both available as part of membership to the Royal College of Psychiatrists and the British Medical Association, 
Table 2 Percentage of psychiatrists ranking selected journals first, second or third with regard to their clinical work (all journals ranked by at least I0\% of psychiatrists in one or more category)

Journal

Patient age-group to whom psychiatric services are provided

\begin{tabular}{|c|c|c|c|c|c|c|c|c|c|c|c|}
\hline \multicolumn{3}{|c|}{ All groups } & \multicolumn{3}{|c|}{ Child } & \multicolumn{3}{|c|}{ Adult } & \multicolumn{3}{|c|}{ Old age } \\
\hline \pm & + & - & \pm & + & - & \pm & + & - & \pm & + & - \\
\hline 81 & 76 & 83 & 71 & 73 & 70 & 89 & 78 & 93 & 85 & 79 & 86 \\
\hline 56 & 50 & 58 & 38 & 42 & 36 & 66 & 54 & 71 & 64 & 53 & 66 \\
\hline 28 & 32 & 27 & 78 & 78 & 78 & 3 & 2 & 3 & I & 0 & I \\
\hline 26 & 23 & 27 & 0 & 0 & 0 & 2 & 0 & 3 & 69 & 79 & 66 \\
\hline 15 & 20 & 13 & 9 & 12 & 7 & 27 & 46 & 20 & 13 & 12 & 14 \\
\hline 10 & 12 & 9 & 27 & 29 & 26 & 1 & 0 & I & 0 & 0 & 0 \\
\hline 7 & 5 & 8 & 6 & 5 & 7 & II & 2 & 15 & 6 & 5 & 6 \\
\hline 6 & 2 & 7 & 16 & 5 & 20 & 0 & 0 & 0 & 0 & 0 & 0 \\
\hline 5 & 4 & 5 & 0 & 0 & 0 & 1 & 0 & 1 & 13 & 14 & 13 \\
\hline 5 & 7 & 5 & 4 & 5 & 3 & 10 & 12 & 9 & 2 & 2 & 3 \\
\hline 3 & 10 & I & 2 & 5 & 0 & 9 & 29 & 2 & 1 & 0 & I \\
\hline 2 & 5 & I & I & 2 & I & 5 & 15 & 2 & I & 2 & I \\
\hline 2 & 3 & I & 0 & 0 & 0 & 5 & 10 & 3 & I & 0 & I \\
\hline
\end{tabular}

\pm , With and without academic commitments; + , with academic commitments;,- , without academic commitments; $*$, journal not listed on the original questionnaire.

respectively. Most psychiatrists, therefore, will receive them without subscription. Because our sample was provided by the Royal College of Psychiatrists from lists of its Members and Fellows, then all will receive the British Journal of Psychiatry. Approximately $80 \%$ of practising doctors are members of the British Medical Association and therefore automatically will receive the $B M J$. In addition, the $B M J$ is freely accessible via the internet. These two journals were noticeably ahead of all the other journals in terms of readership. The British Journal of Psychiatry also contained a significant proportion of the total papers in the whole NHS Research Outputs Database mental health field. It published more than three times as many articles funded in some way by the NHS as the International Journal of Geriatric Psychiatry in second place. Rafferty et al (2000) found that one dominant journal in the field of nursing contained far more publications than any other $(46 \%$ of the total), followed by a second containing $6.5 \%$.

\section{Comparisons with journal impact factors}

The journal impact factor has been used as an indicator of the quality of research published within journals (Schwartz \& Lopez Hellin, 1996). However, our study shows that the correlation between the perceived importance attributed by clinical practitioners in the field of psychiatry and the journal impact factor is neither a simple nor a consistent relationship (see Fig. 1). This was found for clinicians both with and without academic commitments.

The journal impact factor scores of the British Journal of Psychiatry and the BMJ are reasonably high. The British Journal of Psychiatry was positioned eighth out of 81 within the field of psychiatry, and the $B M J$, although obviously not listed in the psychiatry journals, had a journal impact factor that would have put it in third position. Of the top ten journals in the field of psychiatry, according to journal impact factors, only four (Archives of General Psychiatry, Biological Psychiatry, the American Journal of Psychiatry and the British Journal of Psychiatry) were found in the 31 journals with a clinical readership of $10 \%$ or more in any one category (by patient age-group or academic commitments) and the first three of these were found to be of significantly greater importance to academics in the adult group than to any other category of psychiatrist.

In this discussion an inevitable limitation has to be considered. As discussed later, national bias has been found in both publication trends and readership of journals (Grant et al, 2000; Schein et al, 2000), therefore it was felt that a standard list of journals that were most important as outlets for UK psychiatry publications would seem an appropriate starting point for this survey. Including a comparatively small number of such journals enabled a manageable list to be included in the questionnaire, but allowing clinicians to add journal names inevitably created two populations of journals. It would seem reasonable to assume that those journals included within the questionnaire were more likely to be ticked as read than those not included. The Archives of General Psychiatry, which has the highest journal impact factor in the field of psychiatry, was not one of the journals listed on the questionnaire owing to the small number of UK papers published in it. This absence from the questionnaire might have reduced the numbers of psychiatrists referring to the Archives of General Psychiatry but would not account for the marked differences found between academics and nonacademics and between the adult group compared with the other two patient age categories. It is possible of course that papers in journals such as this have an important indirect, rather than direct, influence on clinical practice in the UK through their impact on guidelines, etc.

The Journal of Child Psychology and Psychiatry and Allied Disciplines is widely read and the most highly rated by child psychiatrists, but its journal impact factor 
Table 3 All $3 \mathrm{I}$ journals read by at least $10 \%$ of psychiatrists in one or more category and ranked by the percentage of psychiatrists that read them, their journal impact factors (JIFs) and various ranking methods of JIF

\begin{tabular}{|c|c|c|c|c|c|}
\hline Journal & $\begin{array}{l}\text { \% Psychiatrists } \\
\text { (all categories) } \\
\text { reading the journal }\end{array}$ & $\begin{array}{c}\text { NHS (England) } \\
\text { psychiatry } \\
\text { publications } \\
1990-1999\end{array}$ & JIF 200 I & $\begin{array}{l}\text { Ranking } \\
\text { of the 3I } \\
\text { journals } \\
\text { by JIF }\end{array}$ & $\begin{array}{l}\text { Position in ISI } \\
\text { ranking of the } \\
8 \mathrm{I} \text { psychiatry } \\
\text { journals in SCI by JIF }\end{array}$ \\
\hline British Journal of Psychiatry & 97 & 1049 & 4.1 & 6 & 8 \\
\hline BMJ & 89 & 168 & 6.6 & 4 & - \\
\hline American Journal of Psychiatry & 38 & 41 & 6.9 & 3 & 2 \\
\hline Journal of Child Psychology and Psychiatry and Allied Disciplines & 35 & 64 & 2.8 & 13 & $9^{1}$ \\
\hline International Journal of Geriatric Psychiatry & 30 & 335 & 1.8 & 19 & 38 \\
\hline Psychological Medicine & 29 & 299 & 3.1 & 9 & 15 \\
\hline Lancet & 22 & 74 & 13.3 & $\mathbf{I}$ & - \\
\hline Age and Ageing & 16 & 52 & 1.7 & 20 & - \\
\hline Acta Psychiatrica Scandinavica & 15 & 136 & 2.1 & 16 & 29 \\
\hline *Journal of the American Academy of Child and Adolescent Psychiatry & 14 & 15 & 3.6 & 7 & 11 \\
\hline Journal of Neurology, Neurosurgery and Psychiatry & 13 & 101 & 3.0 & 11 & 16 \\
\hline Hospital Medicine (previously British Journal of Hospital Medicine) & 12 & 79 & 0.3 & 27 & - \\
\hline *Advances in Psychiatric Treatment & II & $\mathrm{N} / \mathrm{A}$ & N/A & $\mathrm{N} / \mathrm{A}$ & $\mathrm{N} / \mathrm{A}$ \\
\hline *Clinical Child Psychology and Psychiatry & 9 & N/A & N/A & N/A & N/A \\
\hline Journal of the Royal Society of Medicine & 9 & 69 & 0.7 & 24 & - \\
\hline Biological Psychiatry & 8 & 61 & 5.5 & 5 & 4 \\
\hline Schizophrenia Research & 7 & 75 & 3.6 & 7 & 12 \\
\hline *Archives of General Psychiatry & 6 & 29 & 12.0 & 2 & I \\
\hline Journal of Affective Disorders & 6 & 114 & 1.9 & 17 & 36 \\
\hline Journal of Psychopharmacology & 6 & 63 & 2.6 & 14 & 20 \\
\hline International Journal of Eating Disorders & 5 & 100 & 1.9 & 17 & 35 \\
\hline *Journal of Family Therapy & 5 & 12 & 0.5 & 26 & - \\
\hline *Psychiatric Bulletin & 5 & N/A & $\mathrm{N} / \mathrm{A}$ & $\mathrm{N} / \mathrm{A}$ & $\mathrm{N} / \mathrm{A}$ \\
\hline Psychopharmacology & 5 & 51 & 3.1 & 9 & 14 \\
\hline International Clinical Psychopharmacology & 4 & 126 & 2.3 & 15 & 26 \\
\hline *Child Abuse and Neglect & 3 & I & 1.2 & 21 & - \\
\hline *Journal of Adolescence & 3 & 14 & 0.8 & 23 & - \\
\hline Social Psychiatry and Psychiatric Epidemiology & 3 & 79 & 1.2 & 21 & $33^{\prime}$ \\
\hline *International Psychogeriatrics & 2 & $\mathrm{~N} / \mathrm{A}$ & $\mathrm{N} / \mathrm{A}$ & $N / A$ & $\mathrm{~N} / \mathrm{A}$ \\
\hline *Ageing and Mental Health & 1 & 32 & 0.6 & 25 & - \\
\hline *Journal of the American Geriatrics Society & 1 & 4 & 2.9 & 12 & - \\
\hline
\end{tabular}

ISI, Institute for Scientific Information; SCI, Science Citation Index; *, journal not listed in original questionnaire; -, journals not included in the ISI's rankings of psychiatry journals in either the $\mathrm{SCl}$ or the Social Science Citation Index; N/A, journals without a JIF.

I. Position of journal based on JIF in ISI ranking of the 77 psychiatry journals in the Social Science Citation Index.

would put it in 17th position if it were included in the Science Citation Index listing for psychiatry in the Journal Citation Reports. The International Journal of Geriatric Psychiatry is similarly widely read within its patient age-group of psychiatrists but is poorly rated by journal impact factor, being positioned 38th in the psychiatry list. Clinical Child Psychology and Psychiatry and Advances in Psychiatric Treatment feature quite prominently in the results of this survey but neither was included in the original questionnaire because neither is listed by the Science Citation Index.

\section{Survey findings in context}

Previous research has raised several relevant issues, including the significance of country of publication and the relevance of journal impact factor to readership patterns. Grant et al (2000) examined UK clinical guidelines to determine the flow of information from basic research to clinical practice and the nationality of papers cited in UK clinical guidelines. They found that UK authors of clinical guidelines cite UK publications in a greater proportion $(25 \%)$ than is found in world biomedical literature $(10 \%)$. Schein et al surveyed 1000 Fellows of the American College of Surgeons and found that they were only interested in American journals, despite the fact that an international survey by e-mail had found a UK journal, the British Journal of Surgery, to be the 'best' general surgical journal in the world (Schein et al, 2000). Furthermore, journal impact factor was 
not a consideration for these surgeons when selecting journals to read. Lewison (2002) examined the relationship between the importance of journals to researchers and to the users of research in a series of medical sub-fields. He found significant variations. In the more clinical subjects such as nursing there was virtually no correlation between their perceived relative importance and the citation score of the journal.

The findings of this survey indicate that in terms of nationality of journals read, and ranked first, second or third, although some of the American journals are of considerable significance there is a clear bias towards journals published in the UK. This bias may, however, have been exaggerated by the choice of journals listed in the original questionnaire.

The study examines what psychiatrists read and perceive as important to their clinical practice, and it covers a large number of publications. Adopting a broad approach in a brief questionnaire inevitably means that some issues were not explored. The term 'read' has not been examined, just as the different sections and article types in the journals have not been analysed individually. Further studies, possibly on a journal-by-journal basis, would provide more information in this area (Tyrer, 2003). Also, there may have been some differences in the respondents' interpretation of the questions asked, which possibly will have had some effect on the findings. A further limitation

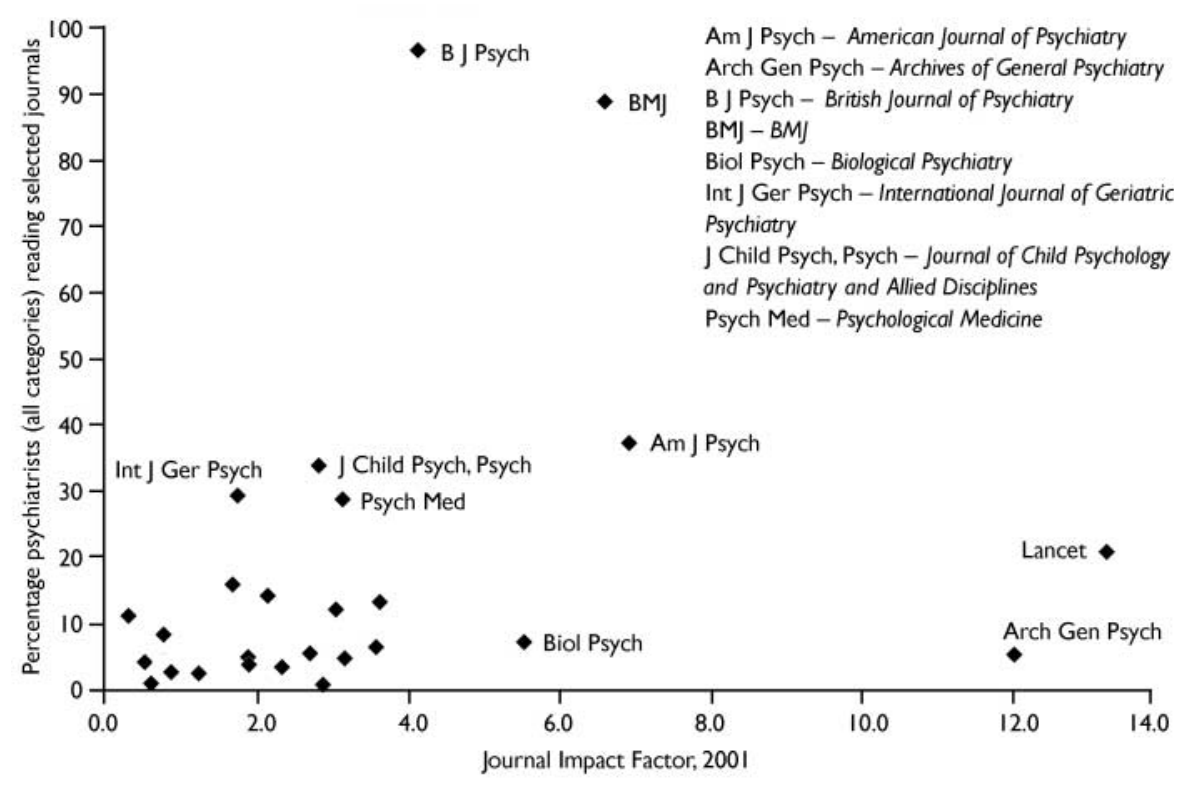

Fig. I Percentage of psychiatrists reading selected journals $v$. journal impact factor 200 I (all journals read by at least $10 \%$ of psychiatrists in one or more category, as in Table 3). Note that the Archives of General Psychiatry was not listed on the original questionnaire.

\section{CLINICAL IMPLICATIONS} findings to journals widely read by clinicians. increased. clinical relevance.

\section{LIMITATIONS} are routinely received by most respondents.

- The response rate was only $47 \%$. of Oxford, Oxford, UK Middlesex UB8 3PH, UK. E-mail: teresa.jones@brunel.ac.uk

- Researchers aiming to inform clinical practice should consider targeting their

- The incentives to researchers to disseminate research to clinicians should be

Journals should be concerned with identifying ways to enhance their perceived

- The two journals ranked highest for readership were 'subscription' journals that

- The study is cross-sectional and therefore is unable to track associations between reading habits and changes in journal impact factors.

TERESA JONES, MSc, STEPHEN HANNEY, PhD, MARTIN BUXTON, BA, Health Economics Research Group, Brunel University, Uxbridge; TOM BURNS, FRCPsych, Department of Psychiatry, Warneford Hospital, University

Correspondence: Teresa Jones, Health Economics Research Group, Brunel University, Uxbridge,

(First received 18 November 2003, final revision 24 March 2004, accepted 5 April 2004)

that has not been examined here involves the variation in journal availability to psychiatrists, with expensive ones available only to some psychiatrists. Research on

Am J Psych - American Journal of Psychiatry B J Psych - British Journal of Psychiatry

sychiatry and Psychiatry and Allied Disciplines Psych Med - Psychological Medicin

(1)
ine the value of research (Buxton \& Hanney, 1996) and, in turn, such analysis (Hanney et al, 2003) is being linked to work on how best to implement research findings (Grimshaw et al, 2001). Perhaps greater recognition should be given to researchers who publish in the journals that are of greatest importance in disseminating research, irrespective of their journal impact factors.

\section{ACKNOWLEDGEMENTS}

Thanks to Avril Cook for meticulously checking the questionnaire data entry prior to analysis. Thanks 
also to all those psychiatrists who responded to our questionnaire survey and to the referees for their constructive comments.

\section{REFERENCES}

Bowker, R. R. (publisher) (2003) Ulrich's International Periodicals Directory: Including Irregular Serials and Annuals (4lst edn). New York: R. R. Bowker.

Buxton, M. \& Hanney, S. (1996) How can payback from health services research be assessed? Journal of Health Services Research \& Policy, I, 35-43.

Coomarasamy, A., Gee, H., Publicover, M., et al (200I) Medical journals and effective dissemination of health research. Health Information and Libraries Journal, 18, |83-19|.

Dawson, G., Lucocq, B., Cottrell, R., et al (1998) Mapping the Landscape: National Biomedical Research Outputs 1988-95. London: Wellcome Trust.
Garfield, E. (1994) The impact factor. Current Contents, 20 June. Available at http://www. isinet.com/essays/ journalcitationreports/7.html/

Grant, J., Cottrell, R., Cluzeau, F., et al (2000) Evaluating 'payback' on biomedical research from papers cited in clinical guidelines: applied bibliometric study. $B M$, 320, II07-IIII.

Grimshaw, J., Shirran, L., Thomas, R., et al (200I) Changing provider behaviour. An overview of systematic reviews of interventions. Medical Care, 39 (suppl. 2), ||2- II 45 .

Hanney, S., Soper, B. \& Buxton, M. (2003) Evaluation of the NHS R\&D Implementation Methods Programme. Uxbridge: Brunel University.

Lewison, G. (2002) Researchers' and users' perception of the relative standing of biomedical papers in different journals. Scientometrics, 53, 229-240.

Lewison, G., Rafferty, A. \& Traynor, M. (200I) Is nursing research typical of biomedical research? Research Evaluation, 10, 97-103.
Medical Research Council (2002) MRC Annual Report and Accounts 01/02. London: Medical Research Council.

Rafferty, A., Traynor, M. \& Lewison, G. (2000)

Measuring the Outputs of Nursing R\&D. A Third Working Paper. London: Centre for Policy in Nursing Research.

Schein, M., Paladugu, R., Sutija, V., et al (2000) What American surgeons read: a survey of a thousand Fellows of the American College of Surgeons. Current Surgery, 57 , 252-258.

Schwartz, S. \& Lopez Hellin, J. (1996) Measuring the impact of scientific publications. The case of the biomedical sciences. Scientometrics, 35, 119-132.

Tomlinson, S. (2000) The research assessment exercise and medical research. BMJ, 320, 636-639.

Tyrer, P. (2003) A new dawn for the yellow journal? Editor's response (letter). British Journal of Psychiatry, 183, 459-465.

Wellcome Trust \& NHS Executive (2001) Putting NHS Research on the Map. An Analysis of Scientific Publications in England, 1990-97. London: Wellcome Trust and NHS Executive. 


\section{APPENDIX}

\section{A study of which peer-reviewed journals are read and perceived as} important by clinical practitioners in the field of mental health

I. Please tick up to ten journals in total that you read or consult on a regular basis with regard to your clinical work and then rank the top three of these (i.e. I, 2 or 3). Please add any journals you feel are of importance in the context of mental health clinical practice.

\begin{tabular}{|c|c|c|}
\hline Name of journal & $\begin{array}{l}\text { Tick up } \\
\text { to } 10\end{array}$ & $\begin{array}{l}\text { Rank } \\
\text { top } 3\end{array}$ \\
\hline ACTA PSYCHIATRICA SCANDINAVICA & $\square$ & $\square$ \\
\hline AGE AND AGEING & $\square$ & $\square$ \\
\hline AMERICAN JOURNAL OF MEDICAL GENETICS & $\square$ & $\square$ \\
\hline AMERICAN JOURNAL OF PSYCHIATRY & $\square$ & $\square$ \\
\hline BEHAVIOUR RESEARCH AND THERAPY & $\square$ & $\square$ \\
\hline BIOLOGICAL PSYCHIATRY & $\square$ & $\square$ \\
\hline BRITISHJOURNAL OF PSYCHOLOGY & $\square$ & $\square$ \\
\hline BRITISHJOURNAL OF GENERAL PRACTICE & $\square$ & $\square$ \\
\hline BRITISHJOURNAL OF HOSPITAL MEDICINE & $\square$ & $\square$ \\
\hline BRITISHJOURNAL OF MEDICAL PSYCHOLOGY & $\square$ & $\square$ \\
\hline BRITISHJOURNAL OF PSYCHIATRY & $\square$ & $\square$ \\
\hline BRITISH MEDICAL JOURNAL & $\square$ & $\square$ \\
\hline HUMAN PSYCHOPHARMACOLOGY - CLINICAL AND EXPERIMENTAL & $\square$ & $\square$ \\
\hline INTERNATIONAL CLINICAL PSYCHOPHARMACOLOGY & $\square$ & $\square$ \\
\hline INTERNATIONAL JOURNAL OF EATING DISORDERS & $\square$ & $\square$ \\
\hline INTERNATIONAL JOURNAL OF GERIATRIC PSYCHIATRY & $\square$ & $\square$ \\
\hline IRISH JOURNAL OF PSYCHOLOGICAL MEDICINE & $\square$ & $\square$ \\
\hline JOURNALOFADVANCED NURSING & $\square$ & $\square$ \\
\hline JOURNAL OF AFFECTIVE DISORDERS & $\square$ & $\square$ \\
\hline JOURNAL OF CHILD PSYCHOLOGY AND PSYCHIATRY AND ALLIED DISCIPLINES & $\square$ & $\square$ \\
\hline JOURNAL OF FORENSIC PSYCHIATRY & $\square$ & $\square$ \\
\hline JOURNAL OF NEUROLOGY, NEUROSURGERY AND PSYCHIATRY & $\square$ & $\square$ \\
\hline JOURNALOF PSYCHOPHARMACOLOGY & $\square$ & $\square$ \\
\hline JOURNAL OF PSYCHOSOMATIC RESEARCH & $\square$ & $\square$ \\
\hline JOURNAL OF THE ROYAL SOCIETY OF MEDICINE & $\square$ & $\square$ \\
\hline LANCET & $\square$ & $\square$ \\
\hline MEDICINE, SCIENCE AND THE LAW & $\square$ & $\square$ \\
\hline NEUROSCIENCE LETTERS & $\square$ & $\square$ \\
\hline PSYCHOLOGICAL MEDICINE & $\square$ & $\square$ \\
\hline PSYCHOPHARMACOLOGY & $\square$ & $\square$ \\
\hline SCHIZOPHRENIA RESEARCH & $\bar{\square}$ & $\square$ \\
\hline SOCIAL PSYCHIATRY AND PSYCHIATRIC EPIDEMIOLOGY & $\square$ & $\square$ \\
\hline
\end{tabular}

2. What type of NHS contract do you have?

Whole time

Maximum part-time

Part-time

Honorary

Other

3. How many clinical sessions per week do you work? . ... .

4. How many academic sessions per week do you work? .......

5. In which subgroup do you work? (Please tick as many as necessary)

Childhood and adolescence

Adults of working age

Old age psychiatry

Liaison psychiatry

6. With which disorders do you work? (Please tick as many as necessary)

Anxiety disorders

Phobias

Bipolar disorders

Schizophrenia

Conduct disorders

Suicide and self-harm

The dementias

Alcohol, drug or substance abuse

Depression

Eating disorders

Learning difficulties

Other

Obsessive-compulsive disorder

(Please specify 